\title{
Papilomavírus humano e neoplasia cervical
}

\author{
Human papillomavirus and cervical neoplasia
}

\author{
${ }^{1}$ Curso de Medicina, \\ Universidade do Extremo \\ Sul Catarinense, Criciúma, \\ Brasil. \\ 2 Programa de Pós-gradu- \\ ação em Ciências da Saúde, \\ Universidade do Extremo \\ Sul Catarinense, Criciúma, \\ Brasil. \\ 3 Programa de Pós-gradu- \\ ação em Epidemiologia, \\ Universidade Federal do Rio \\ Grande do Sul, Porto Alegre, \\ Brasil. \\ 4 Programa de Pós-gradu- \\ ação em Ciências Médicas, \\ Universidade Federal do Rio \\ Grande do Sul, Porto Alegre, \\ Brasil. \\ Correspondência \\ M. I. Rosa \\ Curso de Medicina \\ Universidade do Extremo Sul \\ Catarinense. \\ Rua Cruz e Souza 510, \\ Criciúma, $S C$ \\ 88811-550, Brasil. \\ mir@unesc.net
}

\section{Abstract}

Human papillomavirus (HPV) has been established as an important etiological factor for the development of cervical cancer. This DNA virus primarily infects the epithelium and can induce benign and malignant lesions of the mucous membranes and skin. Some HPVs are considered high risk due to their role in malignant progression of cervical tumors. Genital HPV infections are common and usually transient among young sexually active women. Only a small fraction of infected women develop cervical cancer, implying the involvement of environmental and genetic cofactors in cervical carcinogenesis. Classification, virology, pathology, natural history, epidemiological features of genital HPV infection, and future prospects for cervical cancer prevention with $H P V$ vaccines will be reviewed here.

Cervical Intraepithelial Neoplasia; Papillomavirus Infections; DNA Viruses

\author{
Maria Inês da Rosa 1,2 \\ Lídia Rosi Medeiros ${ }^{3}$ \\ Daniela Dornelles Rosa 4 \\ Mary Clarisse Bozzeti ${ }^{3}$ \\ Fábio Rosa Silva ${ }^{1}$ \\ Bruno Rosa Silva 1
}

\section{Introdução}

O câncer cervical é responsável por $6 \%$ de todas as neoplasias entre mulheres, com cerca de 500 mil novos casos diagnosticados a cada ano 1 . Aproximadamente 231 mil mulheres morrem anualmente por câncer cervical invasivo, sendo que $80 \%$ dessas mortes ocorrem em países subdesenvolvidos 1,2

Na década de 1970, contrariando as teorias existentes, Hausen afirmou que se as células cancerosas contivessem um vírus oncogênico, elas poderiam apresentar o DNA viral em seu genoma. Em 1983, descobriu o papilomavírus humano tipo 16 (HPV16) que, juntamente com o HPV18, está presente em $70 \%$ das biópsias feitas em pacientes com câncer cervical 3,4. Harald zur Hausen foi um dos ganhadores do Prêmio Nobel de Medicina em 20085.

A International Agency for Research on Cancer (IARC), em 1995, conduziu um estudo multicêntrico de casos e controles com 2 mil casos de câncer cervical e 2 mil controles. A análise mostrou uma forte associação entre câncer cervical e a presença de qualquer tipo de HPV. A odds ratio (OR) de todos os países, ajustada pela idade, foi de 60 (IC95\%: 49-73) 6. Observa-se que o risco da associação entre HPV e câncer cervical em alguns estudos é maior do que 100 7. Nenhum outro fator de risco para neoplasia cervical tem magnitude comparável 8. Entretanto, a infecção pelo HPV é necessária, mas não suficiente, para 
causar o câncer cervical 9,10. A vasta maioria das mulheres infectadas pelo HPV oncogênico nunca desenvolverão câncer, sugerindo que fatores adicionais devam agir em conjunto para o desenvolvimento da doença.

Com o objetivo de contribuir para um melhor conhecimento do HPV na etiopatogênese do câncer cervical, desenvolveu-se essa revisão de literatura.

\section{Estrutura viral}

Segundo o International Committee on Taxonomy of Viruses (ICTV), o HPV está classificado atualmente na família Papillomaviridae (antiga Papovaviridae) 11. Seu genoma é composto por uma dupla hélice de DNA circular, com aproximadamente 8 mil pares de bases. O genoma é pequeno e contém apenas alguns genes, todos codificados na mesma cadeia. O capsídeo é icosaédrico, com um diâmetro de 50 a $60 \mathrm{~nm}$ e não é revestido por envelope lipídico 12 .

O genoma viral é constituído por um DNA de fita dupla circular variando de 5 a 8 Kbp de tamanho dividido em região reguladora (LCR - long control region), que contém a origem de replicação (ORI) e a maioria dos promotores de transcrição. As regiões codificadoras são denominadas ORF (open reading frames), que são divididas nas seqüências precoce e tardia 13 . A região precoce (E - early) codifica as proteínas envolvidas na replicação do DNA viral e transformação celular das quais se destacam E1, E2, E6 e E7 12 e região tardia ( $\mathrm{L}$ - late), codifica as proteínas do capsídeo (L1 e L2), responsáveis pelas etapas finais da replicação do vírus, como a síntese de proteínas estruturais do capsídio 14,15.

A descoberta de que a proteína L1 é capaz de organizar-se em partículas de estrutura icosaédrica, semelhantes ao capsídeo viral, VLPs (virus-like particles), mas sem o DNA do vírus, possibilitou o avanço do conhecimento sobre a imunogênese do HPV e o desenvolvimento das vacinas profiláticas 16 .

\section{Classificação}

Foram identificados mais de 100 tipos de HPVs que são antigênicamente semelhantes. A classificação dentro de uma mesma espécie de HPV é baseada na homologia de seu genoma. Para serem considerados de um mesmo tipo não podem variar mais do que $2 \%$ na região codificante ORF e 5\% na região LCR. Sendo assim, pequenas variações no seu genoma originam diferentes tipos de HPV. Cerca de 40 tipos atingem a região anogenital, dos quais, aproximadamente, 18 são oncogênicos: HPV16, 18, 26, 31, 33, 35, 39, 45, $51,52,53,56,58,59,63,66,68$ e 82 15. Os demais tipos genitais, HPV6, 11, 42, 43 e 44 são considerados de baixo risco ou sem qualquer risco oncogênico 17 .

\section{Patologia da infecção pelo HPV}

Apresentam tropismo celular, devido à presença de receptores específicos, cuja replicação é limitada a células de tecidos em diferenciação. A infecção se inicia na camada basal da epiderme, em decorrência da abrasão e micro lesões da pele ou mucosa. Na camada proliferativa o vírus pode se replicar e expressar suas proteínas precoces. No entanto, a replicação vegetativa do DNA, ou seja, a síntese de proteínas do capsídeo e a montagem de partículas virais, só têm lugar nas células mais diferenciadas 18 .

Todos os tipos de HPVs são replicados exclusivamente no núcleo da célula hospedeira. Em lesões de pele benignas, associadas ao HPV, o genoma viral encontra-se separado do DNA celular e surge como um plasmídio extra-cromossômico (corpo epissomal). Nas lesões malignas, que não fazem parte da história natural do HPV, o DNA viral se integra aos cromossomos hospedeiros 19,20. Para integrar-se ao DNA celular, é necessário que haja uma quebra no genoma viral. Esta separação não ocorre de forma aleatória, pois a maioria ocorre nas regiões E1 e E2 do vírus. O resultado dessa quebra é uma perda de função desses dois genes, acompanhada de uma desregulação dos genes E6 e E7, resultando em transformação da célula hospedeira 21 .

Existe uma série de proteínas que regulam e controlam o ciclo celular. O gene supressor de tumor p53 codifica uma proteína que é essencial para o controle do ciclo celular. A proteína p53 atua no ciclo celular nos pontos de controle G1/S e G2/M, levando a uma parada nesses pontos e permitindo o reparo de possíveis danos no DNA. Dessa forma, é evitada a replicação de DNA contendo alterações genéticas. A parada no ciclo celular em G1, após a ativação da p53, envolve a transcrição do gene codificante da proteína p21/ WAF inibidora de quinases dependentes de ciclinas (CDKs) 22. Outro gene supressor de tumor é o pRb. Várias proteínas inibidoras auxiliam no controle do ciclo celular. Entre elas a p15 e p16, que atuam bloqueando componentes essenciais para progressão do ciclo celular, como CDK e ciclinas, impedindo o avanço do ciclo da fase G1 para S. As CDKs fosforilam a proteína Rb, provocando uma alteração estrutural que leva à liberação da $\mathrm{Rb}$ do complexo E2F. Outros inibidores 
são p21, associado ao proto-oncogene ras, e p53, que monitoram a saúde celular, a integridade de seus cromossomos e a execução correta das diferentes fases do ciclo 23,24 .

A oncoproteína E7 é uma pequena fosfoproteína nuclear constituída por três regiões conservadas (CR1, CR2 e CR3) 25. O gene do retinoblastoma é um importante gene supressor tumoral que está deletado ou mutado em muitas linhagens celulares tumorais. A pRb que normalmente previne a célula da entrada no ciclo celular e regula a transição G1/S, quando ligada à E7, deixa a proteína E2F livre para comandar a divisão celular 26,27. Esta proteína pertence a uma importante família de fatores de transcrição, permitindo a ativação de complexos ciclina-CDK que levam à progressão irrestrita da fase G1 para S do ciclo celular, resultando em proliferação celular anormal 28 .

A atividade supressora tumoral de p53, que normalmente levaria a célula alterada à apoptose, é perdida quando há a ligação da oncoproteína E6. Esta proteína forma um complexo com a proteína E6-AP (E6 associated protein ligase), um membro da família E3 de ubiquitinas ligases, que somente liga-se à p53 quando esta está associada à E6. O complexo E6/E6-AP leva p53 à degradação proteolítica através da via da ubiquitina, diminuindo os níveis de p53 nas células infectadas 28,29.

A E6 induz também, de forma independente, a atividade da telomerase, ativando o promotor da telomerase transcriptase reversa 30,31. A imortalização das células, que ocorre quando existe a ativação da telomerase, é mais um importante fator no desenvolvimento de tumores malignos, incluindo o câncer cervical 32 .

O modo de ação de pRb e p53 na regulação do ciclo celular sugere que a inativação ou modulação da atividade destas duas proteínas podem resultar na proliferação celular das células basais, alterando a sua diferenciação, permitindo então a expansão de um pool e células epiteliais para a replicação de partículas virais.

Os mecanismos de defesa envolvidos na regressão da infecção pelo HPV envolvem a resposta imune mediada por células, sendo necessária uma apresentação adequada aos linfócitos, mediada pelas proteínas HLA (Human Leukocytes Antigens). Falhas nesse processo podem ser responsáveis pela susceptibilidade às doenças. Diversos estudos demonstraram associações entre os alelos ou haplótipos HLA e a infecção pelo HPV. As moléculas HLA de classe II têm um importante papel na resposta imune. Associações entre HLA e câncer cervical ou infecção por HPV têm sido demonstradas em diferentes populações 33 .

\section{História natural da neoplasia cervical}

\section{Prevalência da infecção pelo HPV}

Aproximadamente $40 \%$ das mulheres sexualmente ativas são infectadas pelo HPV 34 . A curva da prevalência está relacionada, na maioria das regiões, com a idade. A baixa prevalência em mulheres mais velhas comparada com as jovens é independente dos hábitos sexuais. Um estudo de coorte observou que $36 \%$ das infecções estavam presentes antes dos 25 anos e apenas 2,8\% acima dos 45 anos 35. Outro estudo encontrou um pico máximo entre 20-24 anos 36 . Na Costa Rica, foi encontrada uma curva bimodal na prevalência de qualquer tipo de HPV estimada por idade 37 . A explicação poderia ser uma reativação de infecções latentes e a possibilidade de alguma falha no sistema imunológico das mulheres mais velhas e também a presença de infecção pelo HIV. Resultados semelhantes foram encontrados na Espanha e na Colômbia 38 . Outro estudo corrobora esses achados, indicando um segundo pico de infecção pelo HPV em mulheres hispânicas 39 .

Recente revisão realizada na América do Sul, África, Europa e Ásia, em 11 diferentes países, compreendendo 15.613 mulheres entre 15 a 74 anos, concluiu que a prevalência (com idade padronizada) de HPV variou de 1,4 na Espanha a 25,6 na Nigéria, sendo que na África $(25,6 \%)$ a prevalência foi cinco vezes maior que na Europa (5,2\%), com prevalência intermediária na América do Sul $(14,3 \%)$ e na Ásia $(8,7 \%) 40$.

No Brasil, o HPV16 é o tipo predominante nos cânceres cervicais invasivos nas regiões Sul, Centro-Oeste, Nordeste, Norte e Sudeste, com prevalências de $52 \%, 57 \%$, 59\%, 43,5\% e $52 \%$, respectivamente. Em relação a outros tipos de HPV (18, 31 e 33), observam-se variações regionais, sendo que na maioria das regiões o segundo mais prevalente é o HPV18, com exceção da Região Centro-Oeste, em que predomina o HPV33, e na Região Nordeste, onde o HPV31 é o segundo em prevalência $41,42,43,44,45$.

\section{Transmissão e aquisição}

A aquisição da infecção cervical pelo HPV é o principal precursor de uma série de eventos que leva ao câncer cervical e tem sido exaustivamente documentado por estudos epidemiológicos e experimentais durante os últimos 15 anos. Apenas a infecção pelo HPV não é capaz de levar a uma transformação maligna, sendo que a história natural das mulheres com diagnóstico de lesões precursoras de baixo grau é caracterizada por re- 
gressão espontânea, e apenas pequena percentagem persiste e evolui para câncer ${ }^{46}$. Estudos epidemiológicos indicam consistentemente que o risco da aquisição é fortemente influenciado por número de parceiros sexuais, idade em que ocorre a primeira relação sexual e comportamento sexual dos parceiros masculinos 47,48 .

O HPV pode ser transmitido por contato direto dos órgãos genitais durante a prática sexual, por relações anais que podem resultar em infecções virais e neoplasias anais e, ocasionalmente, pelo sexo oral 49 .

\section{Persistência e cura}

Devem ser levados em conta os fatores relacionados ao hospedeiro e ao vírus. Sabe-se que os HPVs oncogênicos são importantes na persistência e na progressão da infecção, especialmente o HPV16, seguido pelo HPV18 50. Alguns estudos têm demonstrado associação entre a carga viral e aumento de freqüência de câncer cervical 50,51. A história natural do HPV é a cura. A integração do DNA do HPV no genoma da célula hospedeira usualmente é observada em carcinomas invasivos e em linhagens celulares de carcinoma cervical, mas as lesões benignas e pré-malignas o DNA do HPV usualmente são extracromossômicos. Nos casos que evoluem para câncer, os genomas que estão mantidos de forma epissomal passam, em algum momento, a integrar o genoma da célula do hospedeiro, causando alterações morfológicas da célula, alterando seu controle do ciclo celular e levando a lesões precursoras 52 .

Permanece ainda obscuro o porquê de somente em algumas pacientes haver a integração viral, situação necessária para a transformação maligna das células epiteliais, que se tornam imortais 10,13 . Outra questão que ainda precisa ser entendida é quanto tempo o vírus pode ficar no estado de latência 52 .

A persistência de infecção pode ser definida como a detecção de um mesmo tipo de HPV duas ou mais vezes em certo período, não havendo consenso de quanto tempo seria esse período 52 . A média seria de 6-12 meses, sendo que o HPV oncogênico tipo 16 persiste por um período maior 53,54. A regressão da infecção pelo HPV parece estar relacionada a mecanismos imunológicos humorais 55 e celulares 56 . Fatores nutricionais também parecem estar relacionados ao tempo de cura. Altas concentrações de trans e cis-licopeno parecem reduzir significativamente o tempo de cura da infecção pelo HPV oncogênico 57 . A persistência da infecção é um preditor para o desenvolvimento de neoplasia intra-epitelial cervical (NIC), particularmente pelos HPVs tipo 16 e 1858 .
Uma coorte com 1.425 mulheres em São Paulo mostrou mediana da persistência de positividade do HPV de 4,8 meses para os HPVs não oncogênicos e de 8,1 para os oncogênicos 54 . A média de idade não alterou a média de duração de persistência dos tipos oncogênicos, porém, os não oncogênicos persistiram por maior tempo nas mulheres com menos de 35 anos 54 .

Coorte de 331 mulheres do Arizona, Estados Unidos, encontrou a mediana de regressão da infecção pelo HPV de 9,8 meses para os tipos oncogênicos e 4,3 meses para os tipos não oncogênicos 59 .

\section{Progressão para câncer cervical}

Mulheres com lesões intra-epiteliais escamosas de alto grau e câncer cervical geralmente possuem infecção por HPVs oncogênicos ${ }^{60}$. Aproximadamente $70 \%$ dos cânceres cervicais são causados pelo HPV16 ou 1817 e 90\% das verrugas vulvares são causadas pelos HPVs tipo 6 ou 1161 .

Num estudo em que foram arroladas 20.810 mulheres, foram calculadas as taxas de incidência cumulativa no intervalo de 122 meses para o risco de NIC III ou mais, concluindo-se que a distinção entre HPV16 e 18 de outros tipos poderia identificar as mulheres com alto risco para desenvolver lesões de alto grau ou câncer 62 . A regressão da NIC I é de $60 \%$, e a sua progresssão para câncer invasor é baixa (1\%), enquanto que a NIC II e NIC III tem um risco de $5 \%$ e $12 \%$, respectivamente, de evoluir para carcinoma invasor 63 .

\section{Co-fatores na evolução da neoplasia cervical}

Vários co-fatores têm sido associados com o desenvolvimento do câncer cervical invasivo como paridade, uso de contraceptivos orais, tabagismo, imunossupressão, particularmente relatado em paciente com HIV, infecções com outras doenças sexualmente transmissíveis e deficiências nutricionais 50 . Porém, seus verdadeiros papéis no desenvolvimento do câncer permanecem obscuros.

Idade da sexarca, número de parceiros sexuais e história de DSTs estão ligados ao processo de aquisição do HPV e não são considerados co-fatores para a progressão da infecção pelo vírus 62 .

\section{Uso de anticoncepcional oral}

A influência do comportamento sexual tem sido muito estudada como fator de risco para o câncer cervical. Alguns estudos 50,64,65 encontra- 
ram associação do uso de anticoncepcional oral (ACO) e câncer de colo, porém existem controvérsias. A contracepção hormonal por menos de cinco anos parece não aumentar o risco. Porém, mulheres que referem uso de ACO de 5 a 9 anos tiveram 2,8 vezes maior chance de desenvolver câncer em relação às que nunca o utilizaram. Esse risco aumenta quando a exposição ao ACO é relatada pelo período de mais de dez anos, passando a ser quatro vezes maior. Uma metanálise mostrou que o uso por longa duração aumenta o risco de câncer cervical 66. A progesterona (acetato de medroxiprogesterona depo) trimestral não parece aumentar o risco de câncer de colo 67 . Pouco se sabe sobre a ação na carcinogênese dos anticoncepcionais injetáveis mensais, que são muito utilizados na América Latina 68 .

Um estudo de coorte inglês 69 não encontrou associação entre uso de ACO e NIC III, nem em mulheres que relataram uso de ACO por mais de oito anos. Em outro estudo prospectivo com 1.675 mulheres, não foi encontrada associação entre câncer cervical e NIC III com o uso corrente de ACO comparado com mulheres que nunca o haviam utilizado. Uma limitação deste estudo foi o fato de que a informação do uso de ACO foi coletada no momento da alocação das pacientes, tendo havido a possibilidade da descontinuação ou de início de uso de ACO durante o desenvolvimento do estudo. Também as usuárias de ACO tiveram um período de seguimento menor do que as não usuárias, havendo a possibilidade de viés 70 .

O mecanismo pelo qual os hormônios influenciariam na carcinogênese do câncer cervical não está bem esclarecido. Os hormônios promoveriam integração do DNA do HPV no genoma do hospedeiro com desregulação da expressão das proteínas E6 e E7 6. Estudos experimentais in vivo demonstram que existe sinergismo entre longo tempo de exposição ao estrogênio e carcinogênese cervical pelo HPV16 71,72.

\section{Paridade}

Há algum tempo suspeitava-se de que a multiparidade pudesse aumentar o risco do câncer cervical. No entanto, tal associação confundiase com o comportamento sexual. Atualmente alguns estudos de casos e controles confirmam o papel independente da alta paridade como fator de risco para carcinogênese cervical. Um estudo realizado na Costa Rica 50 mostrou um significante aumento na freqüência de câncer cervical e neoplasia epitelial de alto grau associado ao aumento do número filhos. Muñoz et al. 65 avaliaram oito estudos de casos e controles em quatro continentes e constataram que existe uma associação direta entre o número de gestações a termo e o risco de carcinoma escamoso cervical, encontrando uma razão de chances de 3,8 (IC95\%: 2,7-5,5) para seis ou mais gestações versus nenhuma gestação. No estudo inglês 69 , encontrou-se associação limítrofe e no estudo de Castle et al. 70 não foi encontrada associação, o que poderia ser explicado pela baixa paridade da população estudada, e também porque os dados de paridade foram coletados no recrutamento da população. Este estudo teve um seguimento de dez anos e, provavelmente, nesse período tenham ocorrido mudanças no número de gestações a termo nas mulheres do estudo.

Estados nutricional e hormonal, traumatismos e mecanismos imunológicos seriam hipóteses plausíveis para explicar associação entre paridade e neoplasia epitelial de alto grau e câncer cervical. As trocas hormonais induzidas pela gestação poderiam estar relacionadas à persistência ou à progressão do HPV. A sororeatividade é mais alta na mulher não-grávida, sugerindo uma redução da resposta imune-humoral contra o HPV durante a gestação 65,73 . O declínio da paridade poderia explicar a redução de câncer cervical em alguns países.

\section{Tabagismo}

Uma consistente associação entre tabagismo e câncer cervical tem sido demonstrada por diversos estudos. Um estudo de revisão ${ }^{74}$ e uma metanálise 75 evidenciam o papel do fumo como fator de risco para o câncer cervical. O tabagismo passivo também pode estar associado à neoplasia cervical. Um estudo de coorte com dados coletados durante dois censos particulares sobre tabagismo ativo e passivo, em Washington, Estados Unidos, no período de 19631978 e 1975-1994, encontrou, para tabagismo passivo, um risco relativo (RR) de 2,1 (IC95\%: 1,3-3,3) para a coorte de 1963, e de 1,4 (IC95\%: $0,8-2,4)$ para a coorte de 1975 , sendo estatisticamente significante somente na primeira coorte ${ }^{76}$. Os autores discutem a possibilidade de que a proporção de mulheres que trabalham fora aumentou nos últimos anos, diminuindo o tempo de exposição das mesmas ao efeito do tabagismo passivo. Nesse mesmo estudo, o tabagismo ativo obteve RR = 2,6 (IC95\%: 1,7-4,1) e RR = 1,7 (IC95\%: 1,1-2,6) nas coortes de 1963 e 1975, respectivamente. Resultados semelhantes foram encontrados por Wu et al. $77 \mathrm{em}$ mulheres tailandesas, concluindo que o tempo de exposição ao tabagismo passivo é fator de risco para o desenvolvimento do câncer cervical. Outros estudos reportam evidências do aumento do risco de desenvolver NIC de alto grau e câncer 
cervical em tabagistas, com OR de 2,2 em três estudos para quem fumou alguma vez na vida versus quem nunca fumou 65,69,78. Fumar 11 ou mais cigarros ao dia versus nunca ter fumado mostrou OR = 5,9 (IC95\%: 10,0-36,0) para desenvolvimento de NIC de alto grau ou câncer e fumar por dez anos ou mais aumentou a OR para 7,5 (IC95\%: 1,2-46,0) 79 .

A evidência biológica para elucidar esse fator de risco ainda é obscura. A nicotina e outros carcinógenos específicos do tabaco foram encontrados nas células cervicais de mulheres tabagistas 80 . A elevada concentração dos derivados do tabaco tem sido associada à depressão das células de Langerhans 81,82.

\section{Nutrientes antioxidantes}

Nos últimos tempos, tem-se investigado a relação entre consumo de vitaminas e de carotenóides na gênese de câncer 83,84 . A dificuldade de interpretar os estudos é pelo fato de saber-se que o processo de carcinogênese envolve múltiplos fatores, sendo tarefa difícil isolarem um único nutriente como fator causal 85 .

As vitaminas mais estudadas como substâncias quimio-preventivas para o câncer cervical são as vitaminas A, incluindo os carotenóides, e vitamina $\mathrm{E}$, que funcionam como antioxidantes em sistemas biológicos. O beta caroteno é um dos mais de 600 carotenóides existentes conhecidos na natureza. Os carotenóides são os pigmentos que vão do amarelo ao vermelho e que são geralmente encontrados em vegetais. Cerca de $50 \%$ dos carotenóides pode resultar em vitamina A, sendo nomeada pró-vitamina A 86 . O licopeno é o carotenóide mais abundante no plasma sem a atividade pró-vitamina A 87.

A vitamina E é uma substância lipossolúvel e existente na natureza como tocoferóis e tocotrienóis em quatro formas diferentes $(\alpha, \beta, \gamma \mathrm{e} \delta)$, sendo o $\alpha$-tocoferol a forma antioxidante mais ativa e amplamente distribuída 88 .

Poucos estudos de avaliação de nutrientes e risco de câncer cervical controlaram fatores como tabagismo e uso de ACO. Além disso, muitos estudos foram realizados antes do advento do método de cromatografia líquida de alta eficiência, que separa e quantifica o caroteno e seus isômeros 89. Alguns estudos encontraram associação inversa entre $\beta$-caroteno e risco de lesões intraepiteliais 90 e câncer invasivo 91,92. Estudos que pesquisaram a concentração de tocoferol mostraram associação de seus níveis com risco de lesões cervicais precursoras de câncer 90,93,94 e de câncer invasivo 68. Esses dados sugerem que alguns carotenóides podem influenciar a história natural da infecção pelo HPV, embora esta associação ainda seja controversa ${ }^{94}$. É importante notar que esses estudos têm um seguimento de tempo curto, entre 6 a 12 meses.

O estresse oxidativo está relacionado às fases de iniciação e promoção do processo de carcinogênese ${ }^{95}$. Mais estudos, preferencialmente prospectivos e com períodos de seguimento maiores do que um ano, são necessários para examinar a influência de nutrientes antioxidantes na persistência do HPV 96.

\section{Co-infecções}

Alguns estudos têm associado DSTs e carcinogênese cervical, com foco principal na Chlamydia trachomatis. Um estudo multicêntrico com 1.238 casos e 1.100 controles, em sete países diferentes, mostrou que o risco de carcinoma cervical escamoso foi elevado nas mulheres soro positivas para C. trachomatis (OR = 1,8; IC95\%: 1,2-2,7) 97. A C. trachomatis de tipo " $G$ " parece aumentar em 6,6 vezes o risco de desenvolvimento desse tipo de câncer (OR = 6,6; IC95\%: 1,6-27), a do tipo "I" em 3,8 vezes (OR = 3,8; IC95\%: 1,3-11,0) e a do tipo "D" em 2,7 vezes (OR = 2,7; IC95\%: 1,3-5,6) 98. Um estudo de caso e controle encontrou forte evidência na associação do herpes vírus-2 com HPV (OR = 2,19; IC95\%: 1,41-3,4), tendo o estudo feito o controle para fatores de confundimento 97

Permanece ainda pouco entendido o papel das DSTs e seus efeitos biológicos no desenvolvimento de lesões precursoras e câncer de colo uterino. O mecanismo mais provável é a indução da inflamação da cérvice uterina, levando a dano por metabólitos oxidativos. As células infectadas pela $C$. trachomatis secretam maior quantidade de citoquinas, resultando em um estado inflamatório mais acentuado 99. Não existem evidências de que o HPV sozinho induza um processo inflamatório.

A inflamação cervical crônica pode induzir lesão tecidual através da produção indireta de espécies reativas de oxigênio, desencadeando uma cascata inflamatória, diminuindo a imunidade celular e promovendo a angiogênese. Já foi demonstrada a associação entre cervicites e lesão intra-epitelial de alto grau 70 , bem como o aumento da expressão da COX-2 em câncer cervical ${ }^{99}$, sugerindo relação entre processo inflamatório e câncer.

\section{Imunosupressão}

Já é conhecido que pessoas infectadas pelo HIV possuem maiores risco de infecção pelo HPV associado a cânceres anogenitais, quando comparados com indivíduos soronegativos para o HIV 100,101. Num estudo, 7\% das 400 mulheres 
infectadas pelo HIV apresentaram neoplasia intra-epitelial de alto grau, comparado a apenas 1\% das 307 mulheres controles (sem infecção pelo HIV) ( $\mathrm{p}<0,001) 46$. Em outro estudo, foram detectadas lesões precursoras em $42 \%$ das citologias realizadas em mulheres infectadas pelo HIV e em $8 \%$ nas não infectadas, sendo que a metade dos casos de NIC no grupo positivo foi de alto grau 102.

As mulheres com infecção pelo HIV com importante imunossupressão (definida como contagem de células CD4 abaixo de 200 x 106/L) possuem maior risco de desenvolver NIC 103,104. Dados atuais indicam que tanto homens como mulheres infectadas pelo HIV têm um aumento de risco de cânceres anogenitais, comparados à população em geral ${ }^{105}$. O risco varia de acordo com a população. Na Europa, foi observado um aumento do risco no sul, particularmente entre usuárias de drogas injetáveis 105, enquanto que nos Estados Unidos há um aumento no nordeste, particularmente na cidade de Nova Iorque 104.

\section{Vacinas}

Duas vacinas contra o papilomavirus humano foram aprovadas no Brasil: Cervarix da GlaxoSmithKline e Gardasil da Merck Sharp \& Dohme. Ambas contêm a proteína L1 do capsídeo viral, produzidas através de tecnologia recombinante para a obtenção de partículas análogas às virais (VLPs) dos dois vírus mais comuns nos cânceres cervicais: HPV16 e o HPV18. A quantidade de VLPs assim como o sistema adjuvante diferem em cada vacina 106,107,108.

Uma considerável quantidade de trabalhos multicêntricos já foi realizada demonstrando evidências convincentes favoráveis à vacinação anti-HPV. As vacinas são seguras, imunogênicas e efetivas na prevenção de infecções pelo HPV e de lesões precursoras do câncer cervical, mas mesmo com a proteção cruzada para alguns outros tipos de HPV não são capazes de abolir o câncer cervical 109,110,111. Cervarix mostra dados de eficácia contra quase todas as infecções pelo HPV45 e, assim como Gardasil, contra metade da infecções pelo HPV31. Com base nos estudos fase II, as vacinas diferem quanto às respostas de anticorpos: Cervarix induz títulos altos de e sustentados de anticorpos anti-HPV16 e 18 durante 5,5 anos e Gardasil induz títulos inicialmente altos de anticorpos anti-HPV18 mas que decaem após três anos 112 .

Algumas dúvidas ainda devem ser respondidas e investigadas: Qual o tempo de duração da imunidade da vacina? Existirá um marcador imunológico para aferir a proteção? Qual a real proteção cruzada contra outros tipos de HPV? Qual o impacto dos outros tipos virais do HPV para os quais a vacina não confere imunidade? A importância do exame de Papanicolaou não será delegada ao segundo plano? Em sentindose protegidas contra o HPV, as mulheres vacinadas não contribuirão para o aumento de outras DSTs? Sabendo-se do alto custo das vacinas, qual o custo-efetividade da vacinação em termos de saúde pública? Os homens também deveriam ser vacinados?

\section{Conclusões}

Está bem estabelecido que o HPV de alto risco seja o agente responsável pelo câncer cervical, sendo que o HPV16 e o HPV18 são responsáveis por cerca de $70 \%$ de todos os cânceres cervicais. As infecções pelo HPV geralmente são adquiridas nos primeiros anos de vida sexual ativa e o risco é proporcional ao número de parceiros, entretanto, a maioria dessas infecções é transitória em mulheres jovens. As lesões intraepiteliais por HPV podem curar sem tratamento, mas a taxa de cura varia de acordo com a gravidade da lesão, lembrando-se que a lesão de alto grau tem alta taxa de progressão para neoplasia maligna cervical.

A eficácia das vacinas contra o HPV16 e 18 já foi demonstrada em ensaios clínicos e metanálises, e essas são recomendadas para mulheres de 13 a 26 anos. São necessários estudos de acompanhamento da imunogenicidade e de custosefetividade para a incorporação em programas de saúde. 


\section{Resumo}

O papilomavírus humano (HPV) é um fator etiológico bem estabelecido para o câncer cervical. Esse vírus de DNA infecta primariamente o epitélio e pode induzir lesões benignas ou malignas na pele e na mucosa. Alguns HPVs são considerados de alto risco, responsáveis pela progressão das lesões precursoras até câncer cervical. A infecção genital pelo HPVé comum em mulheres jovens e geralmente é transitória. Uma pequena proporção de mulheres infectadas desenvolve câncer cervical, implicando o envolvimento de fatores ambientais e fatores genéticos na carcinogênese. Essa revisão aborda a estrutura viral, classificação e patologia do $H P V$, história natural e fatores de risco para neoplasia cervical e perspectivas futuras com a vacina anti-HPV.

Neoplasia Intra-Epitelial Cervical; Infecções por Papilomavirus; Vírus DNA

\section{Referências}

1. Parkim DM. Global cancer statistics in year 2000 . Lancet Oncol 2001; 2:533-43.

2. Boring CC, Squires TS, Tong T, Montgomery S. Cancer statistics, 1994. CA Cancer J Clin 1994; 44:7-26.

3. zur Hausen H. Papillomaviruses causing cancer: evasion from host-cell control in early events in carcinogenesis. J Natl Cancer Inst 2000; 92:690-8.

4. Dürst M, Gissmann L, Ikenberg H, zur Hausen H. A papillomavirus DNA from a cervical carcinoma and its prevalence in cancer biopsy samples from different geographic regions. Proc Natl Acad Sci U S A 1983; 80:3812-5.

5. The Nobel Foundation. 2008 Nobel Prize winner "for his discovery of human papilloma viruses causing cervical cancer”. http://nobelprize.org (acessado em 06/Out/2008).

6. IARC Working Group on Evaluation of Cervical Cancer Screening Programmes. Screening for squamous cervical cancer: duration of low risk after negative results of cervical cytology and its implication for screening policies. BMJ 1986; 293 659-64.

\section{Colaboradores}

Todos os autores participaram da análise crítica dos artigos selecionados e da redação do texto.
7. Duarte-Franco E, Franco EL. Cancer of the uterine cervix. BMC Womens Health 2004; 4 Suppl 1:S13.

8. Bosch FX, Lorincz A, Munoz N, Meijer CJ, Shah KV. The causal relation between human papillomavirus and cervical cancer. J Clin Pathol 2002; 55: 244-65.

9. Walboomers JM, Jacobs MV, Manos MM, Bosch FX Kummer JA, Shah KV. Human papillomavirus is a necessary cause of invasive cervical cancer worldwide. J Pathol 1999; 189:12-9.

10. Ferenczy A, Franco E. Persistent human papillomavirus infection and cervical neoplasia. Lancet Oncol 2002; 3:11-6.

11. International Committee on Taxonomy of Viruses. ICTV approved virus orders, families and genera. http://www.ncbi.nlm.nih.gov/ICTVdb/Ictv/index. htm (acessado em 24/Out/2008).

12. Buck CB, Cheng N, Thompson CD, Lowy DR, Steven AC, Schiller JT, et al. Arrangement of L2 within the papillomavirus capsid. J Virol 2008; 82:5190-7. 
13. Southern SA, Herrington CS. Molecular events in uterine cervical cancer. Sex Transm Infect 1998; 74:101-9.

14. Finnen RL, Erickson KD, Chen XS, Garcea RL, Interactions between papillomavirus L1 and L2 capsid proteins. JVirol 2003; 77:1410-26.

15. Florin L, Sapp C, Streeck RE, Sapp M. Assembly and translocation of papillomavirus capsid proteins. J Virol 2002; 76:10009-14.

16. Christensen ND, Höopfl R, Diangelon SL, Cladel NM, Patrick SD, Welsh PA, et al. Assembled baculovirus - expressed human papillomavirus type 11 L1 capsid protein virus - like - particles are recognized by neutralizing monoclonal antibodies and induce high titres of neutralizing antibodies. J Gen Virol 1994; 75:2271-6.

17. Muñoz N, Bosch FX, Sanjose S, Herrero R, Castellsague $\mathrm{X}$, Shah KV, et al. Epidemiologic classification of human papillomavirus types associated with cervical cancer. N Engl J Med 2003; 348:518-27.

18. Sanclemente G, Gill DK. Human papillomavirus molecular biology and pathogenesis. J Eur Acad Dermatol Venereol 2002; 16:231-40.

19. Kaufman RH, Adam E, Vonka V. Human papillomavirus infection and cervical carcinoma. Clin Obstet Gynecol 2000; 43:363-80.

20. Burd EM. Human papillomavirus and cervical cancer. Clin Microbiol Rev 2003; 16:1-17.

21. Jeon S, Lambert PF. Integration of human papillomavirus type 16 DNA into the human genome leads to increased stability of E6 and E7 mRNAs: implications for cervical carcinogenesis. Proc Natl Acad Sci U S A 1995; 92:1654-8.

22. Albrechtsen N, Dornreiter I, Grosse F, Kim E, Wiesmuller L, Deppert W. Maintenance of genomic integrity by p53: complementary roles for activated and non-activated p53. Oncogene 1999; 18: 7706-17.

23. Dey D, Dahl J, Cho S, Benjamin TL. Induction and bypass of p53 during productive infection by polyomavirus. J Virol 2002; 76:9526-32.

24. Alunni-Fabroni M, Littlewood T, Deleu L, Caldeira S, Giarrè M, DellÓrco M, et al. Induction of S phase and apoptosis by the human papillomavirus type $16 \mathrm{E} 7$ protein are separable events in immortalized rodent fibroblasts. Oncogene 2000; 19:2277-85.

25. Liu X, Clements A, Zhao K, Marmorstein R. Structure of human papillomavirus E7 oncoprotein and its mechanisms for inactivation of the retinoblastoma tumor suppressor. J Biol Chem 2006; 281:578-86.

26. Kastan MB, Bartc J. Cell cycle checkpoints and cancer. Nature 2004; 432:316-23.

27. Motoyama S, Ladines-Llave CA, Luis Villanueva S, Maruo T. The role of human papilloma virus in the molecular biology of cervical carcinogenesis. Kobe J Med Sci 2004; 50:9-19.

28. Scheffner M, Whitaker NJ. Human papillomavirus induced carcinogenesis and the ubiquitin-proteasome system. Semin Cancer Biol 2003; 13:59-67.

29. Thomas M, Banks L. Human pappillomavirus (HPV) E6 interactions with Bak are conserved amongst E6 proteins from high and low risk HPV types. J Gen Virol 1999; 80:1513-7.
30. Klingelhutz AJ, Foster SA, McDougall JK. Telomerase activation by the $\mathrm{E} 6$ gene product of human papillomavirus type16. Nature 1996; 996:79-82.

31. Veldman T, Liu X, Yuan H, SchlegeL R. Human pappillomavirus $\mathrm{E} 6$ and Myc proteins associate in vivo and bind to a cooperatively activate the telomerase reverse transcriptase promoter. Proc Natl Acad Sci U S A 2003; 100:8211-6.

32. Rosa MI, Medeiros LR, Bozzetti MC, Fachel J, Wendland E, Zanini RR, et al. Accuracy of telomerase in cervical lesions: a systematic review. Int J Gynecol Cancer 2007; 17:1205-14.

33. Araujo-Souza PS, Maciag PC, Ribeiro KB, Petzl-Erler ML, Franco EL, Villa LL. Interaction between polymorphisms of the human leukocyte antigen and HPV-16 variants on the risk of invasive cervical cancer. BMC Cancer 2008; 8:246.

34. Ho GY, Bierman R, Beardsley L, Chang CJ, Burk RD. Natural history of cervicovaginal papillomavirus infection in young women. N Engl J Med 1998; 338:423-8.

35. Burk RD, Kelly P, Feldman J, Bromberg J, Vermund SH, DeHovitz JA, et al. Declining prevalence of cervicovaginal human papillomavirus infection with age is independent of other risk factors. Sex Transm Dis 1996; 23:333-41.

36. Melkert PW, Hopman E, van den Brule AJ, Risse EK, van Diest PJ, Bleker OP, et al. Prevalence of HPV in cytomorphologically normal cervical smears, as determined by the polymerase chain reaction, is age-dependent. Int J Cancer 1993; 53:919-23.

37. Herrero R, Hildesheim A, Bratti C, Sherman ME, Hutchinson M, Morales J, et al. Population-based study of human papillomavirus infection and cervical neoplasia in rural Costa Rica. J Natl Cancer Inst 2000; 92:464-74.

38. Muñoz N, Bosch FX, Sanjosé S, Tafur L, Izarzugaza I, Gili M, et al. The causal link between human papillomavirus and invasive cervical cancer: a population-based case-control study in Colombia and Spain. Int J Cancer 1992; 52:743-9.

39. Giuliano AR, Papenfuss MR, Denman CA, Zapien JG, Abrahamsen M, Hunter JB. Human papillomavirus prevalence at the USA-Mexico border among women 40 years of age and older. Int J STD AIDS 2005; 16:247-51.

40. Clifford GM, Gallus S, Herrero R, Muñoz N, Snijders PJ, Vaccarella S, et al. Worldwide distribution of human papillomavirus types in cytologically normal women in the International Agency for Research on Cancer HPV prevalence surveys: a pooled analysis. Lancet 2005; 366:991-8.

41. Lorenzato F, Ho L, Terry G, Singer A, Santos LC, De Lucena-Batista $\mathrm{R}$, et al. The use of human papillomavirus typing in detection of cervical neoplasia in Recife (Brazil). Int J Gynecol Cancer 2000; 10:143-50.

42. Rabelo-Santos SH, Zeferino L, Villa LL, Sobrinho JP, Amaral RG, Magalhães AV. Human papillomavirus prevalence among women with cervical intraepithelial neoplasia III and invasive cervical cancer from Goiânia, Brazil. Mem Inst Oswaldo Cruz 2003; 98:181-4. 
43. Cavalcanti SM, Zardo LG, Passos MR, Oliveira LH. Epidemiological aspects of human papillomavirus infection and cervical cancer in Brazil. J Infect 2000; 40:80-7.

44. Noronha V, Mello W, Villa L, Brito A, Macedo R, Bisi F, et al. Human papillomavirus associated with uterine cervix lesions. Rev Soc Bras Med Trop 1999; 32:235-40.

45. Bosch FX, Manos MM, Muñoz N, Sherman M, Jansen AM, Peto J, et al. Prevalence of human papillomavirus in cervical cancer: a worldwide perspective. International Biological Study on Cervical Cancer (IBSCC) Study Group. J Natl Cancer Inst 1995; 87:796-802.

46. Wright Jr. TC, Ellerbrock TV, Chiasson MA, Van Devanter N, Sun XW. Cervical intraepithelial neoplasia in women infected with human immunodeficiency virus: prevalence, risk factors, and validity of Papanicolaou smears. New York Cervical Disease Study. Obstet Gynecol 1994; 84:591-7.

47. Franco EL, Duarte-Franco E, Ferenczy A. Cervical cancer: epidemiology, prevention and the role of human papillomavirus infection. CMAJ 2001; 164:1017-25

48. Wellings K, Field J, Johnson A, Wadsworth J. Sexual behaviour in Britain - The National Survey of Sexual Attitudes and Lifestyles. London: Penguin Books; 1994.

49. Ford K, Reed B, Wirawan D, Muliawan P, Sutarga M, Gregoire L. The Bali STD/AIDS Study: human papillomavirus infection among female sex workers. Int J STD AIDS 2003; 14:681-7.

50. Hildesheim A, Wang SS. Host and viral genetics and risk of cervical cancer: a review. Virus Res 2002; 89:229-40.

51. Ylitalo N, Sorensen P, Josefsson AM, Magnusson PK, Andersen PK, Ponten J, et al. Consistent high viral load of human papillomavirus 16 and risk of cervical carcinoma in situ: a nested case-control study. Lancet 2000; 355:2194-8.

52. Schiffman M, Kjaer SK. Chapter 2: natural history of anogenital humam papillomavirus infection and neoplasia. J Natl Cancer Inst Monogr 2003; (31):14-9.

53. Liaw KL, Hildesheim A, Burk RD, Gravitt P, Wacholder S, Manos MM, et al. A prospective study of human papillomavirus (HPV) type 16 DNA detection by polymerase chain reaction and its association with acquisition and persistence of other HPV types. J Infect Dis 2001; 183:8-15.

54. Franco EL, Villa LL, Sobrinho JP, Prado JM, Rousseau MC, Desy M, et al. Epidemiology of acquisition and clearance of cervical human papillomavirus infection in women from a high-risk area for cervical cancer. J Infect Dis 1999; 180:1415-23.

55. Bontkes HJ, de Gruijl TD, Walboomers JM, Schiller JT, Dillner J, Helmerhorst TJ, et al. Immune responses against human papillomavirus (HPV) type 16 virus-like particles in a cohort study of women with cervical intraepithelial neoplasia. II. Systemic but not local IgA responses correlate with clearance of HPV-16. J Gen Virol 1999; 80 (Pt 2):409-17.
56. de Gruijl TD, Bontkes HJ, Walboomers JM, Stukart MJ, Doekhie FS, Remmink AJ, et al. Differential T helper cell responses to human papillomavirus type 16 E7 related to viral clearance or persistence in patients with cervical neoplasia: a longitudinal study. Cancer Res 1998; 58:1700-6.

57. Sedjo RL, Roe DJ, Abrahamsen M, Harris RB, Craft $\mathrm{N}$, Baldwin S, et al. Vitamin A, carotenoids, and risk of persistent oncogenic human papillomavirus infection. Cancer Epidemiol Biomarkers Prev 2002; 11:876-84.

58. Schlecht NF, Kulaga S, Robitaille J, Ferreira S, Santos M, Miyamura RA, et al. Persistent human papillomavirus infection as a predictor of cervical intraepithelial neoplasia. JAMA 2001; 286:3106-14.

59. Giuliano AR, Sedjo RL, Roe DJ, Harri R, Baldwi S, Papenfuss MR, et al. Clearance of oncogenic human papillomavirus (HPV) infection: effect of smoking (United States). Cancer Causes Control 2002; 13:839-46.

60. Baseman JG, Koutsky LA. The epidemiology of human papillomavirus infections. J Clin Virol 2005; 32 Suppl 1:S16-24.

61. Greer CE, Wheeler CM, Ladner MB, Beutner K, Coyne MY, Liang H, et al. Human papillomavirus (HPV) type distribution and serological response to HPV type 6 virus-like particles in patients with genital warts. J Clin Microbiol 1995; 33:2058-63.

62. Khan MJ, Castle PE, Lorincz AT, Wacholder S, Sherman M, Scott DR, et al. The elevated 10-year risk of cervical precancer and cancer in women with human papillomavirus (HPV) type 16 or 18 and the possible utility of type-specific HPV testing in clinical practice. J Natl Cancer Inst 2005; 97:1072-9.

63. Ostor AG. Natural history of cervical intraepithelial neoplasia: a critical review. Int J Gynecol Pathol 1993; 12:186-92.

64. Lacey Jr. JV, Brinton LA, Abbas FM, Barnes WA Gravitt PE, Greenberg MD, et al. Oral contraceptives as risk factors for cervicar adenocarcinomas and squamous cell carcinomas. Cancer Epidemiol Biomarkers Prev 1999; 8:1079-85.

65. Muñoz N, Franceschi S, Bosetti C, Moreno V, Herrero R, Smith JS, et al. Role of parity and human papillomavirus in cervical cancer: the IARC multicentric case-control study. Lancet 2002; 359:1085-92.

66. Smith JS, Green J, Berrington-de-Gonzalez A, Appleby P, Peto J, Plummer M, et al. Cervical cancer and use of hormonal contraceptives: a systematic review. Lancet 2003; 361:1159-67.

67. World Health Organization. Depot-medroxyprogesterone acetate (DPMA) and cancer: memorandum from a WHO meeting. Bull World Health Organ 1993; 71:669-76.

68. Skegg DCG. Monthly combined injectable contraceptives and neoplasia. Contraception 1994; 49:435-9.

69. Deacon JM, Evans CD, Yule R, Desai M, Binns W, Taylor C, et al. Sexual behaviour and smoking as determinants of cervical HPV infection and of CIN3 among those infected: a case-control study nested within the Manchester cohort. Br J Cancer 2000; 83:1565-72. 
70. Castle PE, Wacholder S, Lorincz AT, Scott DR, Sherman ME, Glass AG, et al. A prospective study of high-grade cervical neoplasia risk among human papillomavirus-infected women. J Natl Cancer Inst 2002; 94:1406-14.

71. Mitrani-Rosenbaum S, Tsvieli R, Tur-Kaspa R. Oestrogen stimulates differential transcription of human papillomavirus type 16 in SiHa cervical carcinoma cells. J Gen Virol 1989; 70(Pt 8):2227-32.

72. Arbeit JM, Howley PM, Hanahan D. Chronic estrogen-induced cervical and vaginal squamous carcinogenesis in human papillomavirus type 16 transgenic mice. Proc Natl Acad Sci U S A 1996; 93:2930-5.

73. Sethi S, Muller M, Schneider A, Blettner M, Smith E, Turek L, et al. Serologic response to the E4, E6, and E7 proteins of human papillomavirus type 16 in pregnant women. Am J Obstet Gynecol 1998; 178:360-4.

74. Kuper H, Boffetta P, Adami HO. Tobacco use and cancer causation: association by tumour type. J Intern Med 2002; 252:206-24.

75. Haverkos HW, Soon G, Steckley SL, Pickworth W. Cigarette smoking and cervical cancer: part I: a meta-analysis. Biomed Pharmacother 2003; 57: 67-77.

76. Trimble CL, Genkinger JM, Burke AE, Hoffman SC, Helzlsouer KJ, Diener-West M, et al. Active and passive cigarette smoking and the risk of cervical neoplasia. Obstet Gynecol 2005; 105:174-81.

77. Wu MT, Lee LH, Ho CK, Liu CL, Wu TN, Wu SC, et al. Lifetime exposure to environmental tobacco smoke and cervical intraepithelial neoplasms among nonsmoking Taiwanese women. Arch Environ Health 2003; 58:353-9.

78. Hildesheim A, Herrero R, Castle PE, Wacholder S, Bratti MC, Sherman ME, et al. HPV co-factors related to the development of cervical cancer: results from a population-based study in Costa Rica. Br J Cancer 2001; 84:1219-26.

79. Olsen AO, Dillner J, Skrondal A, Magnus P. Combined effect of smoking and human papillomavirus type 16 infection in cervical carcinogenesis. Epidemiology 1998; 9:346-9.

80. Prokopczyk B, Cox JE, Hoffmann D, Waggoner E. Identification of tobacco-specific carcinogen in the cervical mucus of smokers and nonsmokers. J Natl Cancer Inst 1997; 89:868-73.

81. Poppe WA, Ide PS, Drijkoningen MP, Lauweryns JM, Van Assche FA. Tobacco smoking impairs the local immunosurveillance in the uterine cervix. An immunohistochemical study. Gynecol Obstet Invest 1995; 39:34-8.

82. Barton SE, Maddox PH, Jenkins D, Edwards R, Cuzick J, Singer A. Effect of cigarette smoking on cervical epithelial immunity: a mechanism for neoplastic change? Lancet 1988; 2:652-4.

83. Byers T, Perry G. Dietary carotenes, vitamin C, and vitamin $\mathrm{E}$ as protective antioxidants in human cancers. Annu Rev Nutr 1992; 12:139-59.

84. Van Poppel G, van den Berg H. Vitamins and cancer. Cancer Lett 1997; 114:195-202.

85. Doll R. The Pierre Denoix Memorial Lecture: nature and nurture in the control of cancer. Eur J Cancer 1999; 35:16-23.
86. Olson JA. Provitamin A function of carotenoids: the conversion of beta-carotene into vitamin A. J Nutr 1989; 119:105-8.

87. Krinsky NI. Carotenoids as antioxidants. Nutrition 2001; 17:815-7.

88. Niki E, Noguchi N, Tsuchihashi H, Gotoh N. Interaction among vitamin $\mathrm{C}$, vitamin $\mathrm{E}$, and beta-carotene. Am J Clin Nutr 1995; 62 (6 Suppl):1322S-6S.

89. Castle PE, Giuliano AR. Chapter 4: genital tract infections, cervical inflammation, and antioxidant nutrients - assessing their roles as human papillomavirus cofactors. J Natl Cancer Inst Monogr 2003; (31):29-34

90. Palan PR, Mikhail MS, Goldberg GL, Basu J, Runowicz CD, Romney SL. Plasma levels of betacarotene, lycopene, canthaxanthin, retinol, and alpha- and tau-tocopherol in cervical intraepithelial neoplasia and cancer. Clin Cancer Res 1996; 2:181-5.

91. Potischman N, Herrero R, Brinton LA, Reeves WC, Stacewicz-Sapuntzakis M, Jones CJ, et al. A casecontrol study of nutrient status and invasive cervical cancer. II. Serologic indicators. Am J Epidemiol 1991; 134:1347-55.

92. Batieha AM, Armenian HK, Norkus EP, Morris JS, Spate VE, Comstock GW. Serum micronutrients and the subsequent risk of cervical cancer in a population-based nested case-control study. Cancer Epidemiol Biomarkers Prev 1993; 2:335-9.

93. Kwasniewska A, Tukendorf A, Semczuk M. Content of alpha-tocopherol in blood serum of human Papillomavirus-infected women with cervical dysplasias. Nutr Cancer 1997; 28:248-51.

94. Knekt P. Serum vitamin E level and risk of female cancers. Int J Epidemiol 1988; 17:281-6.

95. Giuliano AR, Papenfuss M, Nour M, Canfield LM, Schneider A, Hatch K. Antioxidant nutrients: associations with persistent human papillomavirus infection. Cancer Epidemiol Biomarkers Prev 1997; 6:917-23.

96. Cerutti PA. Oxidant stress and carcinogenesis. Eur J Clin Invest 1991; 21:1-5.

97. Smith JS, Bosetti C, Munoz N, Herrero R, Bosch FX, Eluf-Neto J, et al. IARC multicentric case-control study. Chlamydia trachomatis and invasive cervical cancer: a pooled analysis of the IARC multicentric case-control study. Int J Cancer 2004; 111:431-9.

98. Anttila T, Saikku P, Koskela P, Bloigu A, Dillner J, Ikaheimo I, et al. Serotypes of Chlamydia trachomatis and risk for development of cervical squamous cell carcinoma. JAMA 2001; 285:47-51.

99. Kulkarni S, Rader JS, Zhang F, Liapis H, Koki AT, Masferrer JL, et al. Cyclooxygenase-2 is overexpressed in human cervical cancer. Clin Cancer Res 2001; 7:429-34.

100. Palefsky JM, Holly EA. Chapter 6: imunossupression and co-infection with HIV. J Natl Cancer Inst Monogr 2003; (31):41-6.

101. Strickler HD, Burk RD, Fazzari M, Anastos K, Minkoff H, Massad LS, et al. Natural history and possible reactivation of human papillomavirus in human immunodeficiency virus-positive women. J Natl Cancer Inst 2005; 97:577-86. 
102. Conti M, Agarossi A, Parazzini F, Muggiasca ML, Boschini A, Negri E, et al. HPV, HIV infection, and risk of cervical intraepithelial neoplasia in former intravenous drug abusers. Gynecol Oncol 1993; 49:344-8.

103. Conley LJ, Ellerbrock TV, Bush TJ, Chiasson MA, Sawo D, Wright TC. HIV-1 infection and risk of vulvovaginal and perianal condylomata acuminata and intraepithelial neoplasia: a prospective cohort study. Lancet 2002; 359:108-13.

104. Fordyce EJ, Wang Z, Kahn AR, Gallagher BK, Merlos I, Ly S, et al. Risk of cancer among women with AIDS in New York City. AIDS Public Policy J 2000; 15:95-104.

105. Serraino D, Dal Maso L, La Vecchia C, Franceschi S. Invasive cervical cancer as an AIDS-defining illness in Europe. AIDS 2002; 16:781-6.

106. Lowy DR, Schiller JT. Prophylactic human papillomavirus vaccines. J Clin Invest 2006; 116:1167-73.

107. Villa LL, Costa RL, Petta CA, Andrade RP, Ault KA, Giuliano AR, et al. Prophylactic quadrivalent human papillomavirus (types 6, 11, 16, and 18) L1 virus-like particle vaccine in young women: a randomised double-blind placebo-controlled multicentre phase II efficacy trial. Lancet Oncol 2005; 6:271-8.
108. Harper DM, Franco EL, Wheeler CM, Moscickì $\mathrm{AB}$, Romanowski B, Roteli-Martins CM, et al. Sustained efficacy up to 4.5 years of a bivalent L1 virus-like particle vaccine against human papillomavirus types 16 and 18: follow-up from a randomised control trial. Lancet 2006; 367:1247-55.

109. Joura EA, Leodolter S, Hernandez-Avila M, Wheeler CM, Perez G, Koutsky LA, et al. Efficacy of a quadrivalent prophylactic human papillomavirus (types 6, 11, 16, and 18) L1 virus-like-particle vaccine against high-grade vulval and vaginal lesions: a combined analysis of three randomised clinical trials. Lancet 2007; 369:1693-702.

110. Ault KA; Future II Study Group. Effect of prophylactic human papillomavirus L1 virus-like-particle vaccine on risk of cervical intraepithelial neoplasia grade 2 , grade 3 , and adenocarcinoma in situ: a combined analysis of four randomised clinical trials. Lancet 2007; 369:1861-8.

111. Villa LL, Ault KA, Giuliano AR, Costa RL, Petta CA, Andrade RP, et al . Immunologic responses following administration of a vaccine targeting human papillomavirus types $6,11,16$, and 18 . Vaccine 2006; 24:5571-83.

112. Harper DM. Prophylactic human papillomavirus vaccines to prevent cervical cancer: review of the Phase II and III trials. Therapy 2008; 5:313-24.

Recebido em 03/Set/2008

Versão final reapresentada em 06/Nov/2008

Aprovado em 26/Nov/2008 